\title{
Effect of Film Thickness on Structural and Electrical Properties of Sputter-Deposited Nickel Oxide Films
}

\author{
Hao-Long Chen ${ }^{1, *}$, Yang-Ming Lu$^{2}$ and Weng-Sing Hwang ${ }^{1}$ \\ ${ }^{1}$ Department of Materials Science and Engineering, National Cheng Kung University, \\ No. 1, Ta-Hsueh Road, Tainan 70101, Taiwan, R. O. China \\ ${ }^{2}$ Department of Electronic Engineering \& Nano Technology Research and Development Center, \\ Kun Shan University of Technology, 949 Da-Wan Road, Yung-Kang City, Tainan Hsien 71003, Taiwan, R. O. China
}

This work studies dependences of resistivity, carrier concentration, mobility and structural properties on the thickness of nickel oxide (NiO) films deposited onto glass substrates by RF magnetron sputtering in a pure oxygen atmosphere at an RF power $200 \mathrm{~W}$. The electrical properties were measured by Hall Effect measurements. The X-ray diffraction (XRD) and transmission electron microscope (TEM) analyses of nickel oxide films indicates that these films are polycrystalline when the samples are prepared with an unheated substrate $\left(T_{\mathrm{s}}=303 \mathrm{~K}\right)$ and using a substrate at a higher substrate temperature $\left(T_{\mathrm{s}}=673 \mathrm{~K}\right)$. The thickness of the films varied in the range from 50 to $300 \mathrm{~nm}$. The variations of the microstructural parameters, such as crystallite size $(L)$, dislocation density $(\delta)$, stacking fault probability $(\alpha)$, strain $(\varepsilon)$ and density $(D)$, with film thickness and substrate temperature were investigated. The results show the crystallite sizes increaser as the thickness of the film increases. The variation of the dislocation density and the stacking fault probabilities and strain decrease as the thickness increases. The resistivity of NiO film is increased with an increase in film thickness, which is related to the decrease of carrier concentration with film thickness. The NiO film with a thickness of $200 \mathrm{~nm}$ has a minimum resistivity of $0.69 \times 10^{-2} \Omega \mathrm{m}$ when deposited at substrate temperature of $303 \mathrm{~K}$.

(Received December 7, 2004; Accepted March 1, 2005; Published April 15, 2005)

Keywords: nickel oxide films, thickness, hall effect, structural, electrical

\section{Introduction}

Nickel oxide (NiO) thin films with an NaCl-type structure have attractive interest recently because they have excellent chemical stability, favorable optical, electrical and magnetic properties. They have been used as an antiferromagnetic material, ${ }^{1)}$ p-type transparent conducting films, ${ }^{2)}$ material for electrochromic display devices ${ }^{3)}$ and in functional sensor layers for chemical sensors. ${ }^{4)}$ These films have been fabricated using various physical and chemical vapor deposition techniques, such as spray pyrolysis, ${ }^{5)}$ plasmaenhanced chemical vapor deposition ${ }^{6)}$ and reactive sputtering. ${ }^{3)}$ Among these methods, reactive sputtering is the most extensively used. Researches ${ }^{6-10)}$ have been carried out on the dependence of film properties on sputtering parameters. Numerous reference data and previous studies ${ }^{6-10)}$ have demonstrated that superior electric and optical properties of $\mathrm{NiO}$ films can be obtained by reactive sputtering with a sputtering pressure in the range $0.1-1 \mathrm{~Pa}$ and in a pure oxygen atmosphere using a heated substrate.

The influences of film thickness on the structural, optical, magnetic and electrical properties of thin films are very important. Many reports on the effect of size on thin films of various materials have been published. ${ }^{11-15)}$ However, only few works on the dependence of the properties nickel oxide films on film thickness have been published. ${ }^{16)}$

Nickel oxide films obtained by sputtering onto glass substrate at 303 and $673 \mathrm{~K}$ were analyzed to understand the role of film thickness on the structural and electrical properties of the nickel oxide films. The thickness of the films was varied between 50 and $300 \mathrm{~nm}$.

*Graduate Student, National Cheng Kung University

\section{Experimental Methods}

\subsection{Film preparation}

Nickel oxide films were deposited on a Corning 1737 with a $0.7 \mathrm{~mm}$ thick glass substrate by RF magnetron sputtering from an $\mathrm{NiO}$ target with a purity of $99.99 \%$ purity in an atmosphere of pure oxygen. The distance between the target and the substrate was approximately $80-85 \mathrm{~mm}$. The chamber was evacuated to a pressure of under $4 \times 10^{-4} \mathrm{~Pa}$ before deposition. Sputtering deposition was performed at a gas pressure of $1 \mathrm{~Pa}$. The RF power was maintained at a constant $200 \mathrm{~W}$. The substrates were kept at room temperature 303 and $673 \mathrm{~K}$ respectively. The sputtering time was changed to yield different film thicknesses.

\subsection{Film characterization}

A conventional stylus surface-roughness detector (Alphastep 200) was used to measure the thickness of films. The electrical properties of nickel oxide films, including resistivity, carrier concentration and mobility, were measured using a Hall measurement system ("Lake Shore" model 7604 Hall Effect measurement systems). The crystal structure of the deposited films was identified by X-ray diffraction (XRD). XRD patterns of the films were obtained using a Rigaku D/MAX 2500 multipurpose X-ray thin film diffractometer with monochromatic high-intensity $\mathrm{CuK} \alpha$ radiation $(\lambda=0.15418 \mathrm{~nm})$. The microstructure was observed using an ultrahigh resolution analytical electron microscope (HRAEM, Hitachi model HF-2000 field emission transmission electron microscope, Japan and FEG-TEM, Philips Tecnai F30 Field Emission Gun Transmission Microscope, Holland). The surface and in-depth profile $\mathrm{NiO}$ films were analyzed by Auger Electron Spectroscopy (VG. Microlab 310D Auger Electron Spectroscopy). 


\subsection{Structural analysis}

The inter-plane spacings can be calculated given by the Bragg law. ${ }^{17)}$

$$
d_{h k l}=\lambda /(2 \sin \theta)
$$

where $d_{h k l}$ is inter plane spacing ( $d$-spacing); $\lambda=0.15418$ $\mathrm{nm}$ is X-ray wavelength of $\mathrm{CuK} \alpha$ radiation, and $\theta$ is the diffraction angle.

The full-width at half-maximum (FWHM) can be expressed as a linear combination of the contribution from the lattice strain and crystallite size. ${ }^{18,19)}$ The effects of the strain $(\varepsilon)$ and crystallite sizes $(L)$ on the FWHM can be expressed by the following equation (Williamson-Hall method): ${ }^{18,19)}$

$$
\beta(\cos \theta / \lambda)=1 / L+\varepsilon(\sin \theta / \lambda)
$$

where $\beta$ is the measured FWHM (in radians), $\theta$ is the Bragg angle of the peak, $\lambda$ is the $\mathrm{X}$-ray diffraction wavelength, $L$ is the effective crystallite size, and $\varepsilon$ is the effective strain. The strain value obtained from a Williamson-Hall plot serves to indicate the magnitude of the strain distribution of a nonuniform strain state. A crystalline size value can also be obtained from a Williamson-Hall plot through the intercept of the fitted line with the $y$-axis.

The dislocation density $(\delta)$, defined as the length of the dislocation lines per unit volume of crystal, is evaluated using the formula, ${ }^{14,15,20)}$

$$
\delta=\left(n / L^{2}\right)
$$

where $n$ is a factor that equals unity when the dislocation density is minimum and $L$ is the crystallite size.

The stacking fault probability $\alpha$ is the fraction of layers that undergo stacking sequence faults in a given crystal, so fault is expected to be found in $1 / \alpha$ layers. ${ }^{20)}$ The occurrence of stacking faults gives rise to a shift in the peak positions of different reflections with respect to the ideal positions of a fault-free well-annealed sample or a standard sample. Warren and Warekois ${ }^{20,21)}$ proposed a relation between $\alpha$ and the peak shift $\Delta(2 \theta)$. The stacking fault probability $\alpha$ is given by

$$
\alpha=\left[2 \pi^{2} /(45 \sqrt{3} \tan \theta)\right] \Delta(2 \theta)
$$

The stacking fault probabilities were calculated from the shift of the peaks of the X-ray lines of the films with reference to the 2003 JCPDS database No: 89-7130, using eq. (4).

Nickel oxide is a cubic structure. The lattice parameter ' $a$ ' can be evaluated from the relation

$$
a=d \sqrt{h^{2}+k^{2}+l^{2}},
$$

where $h, k$ and $l$ are Miller indices.

The density of nickel oxide films was estimated from ${ }^{22)}$

$$
D=M /\left(6.02 \times 10^{23} \times V\right)
$$

where $M$ is the total mass of the unit cell of NiO; $6.02 \times 10^{23}$ is the Avogadro constant, and $V$ is the volume of unit cell of the $\mathrm{NiO}$.

\section{Results and Discussion}

\subsection{Structural properties}

Figure 1 displays the X-ray diffraction patterns for nickel oxide films, prepared at $200 \mathrm{~W}$ in an atmosphere of pure (a)

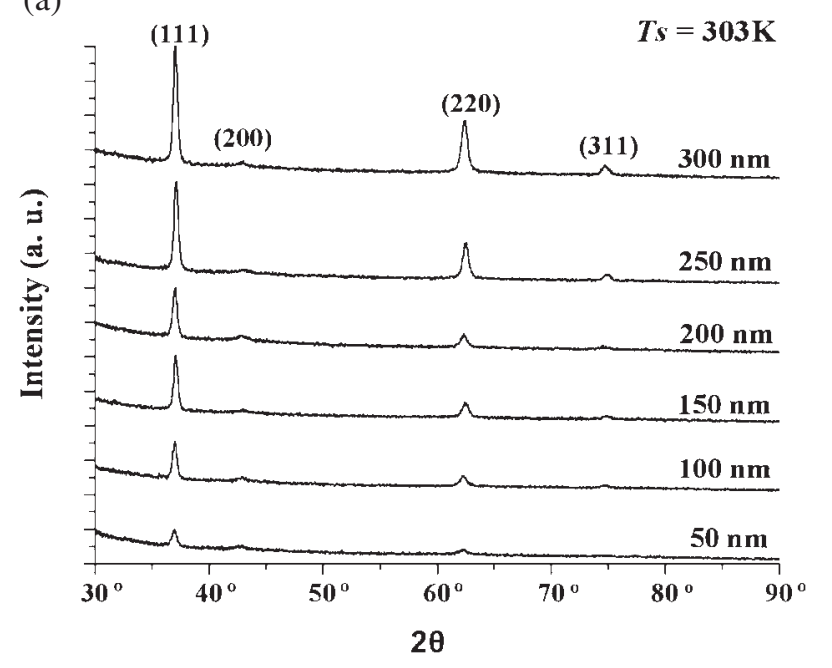

(b)

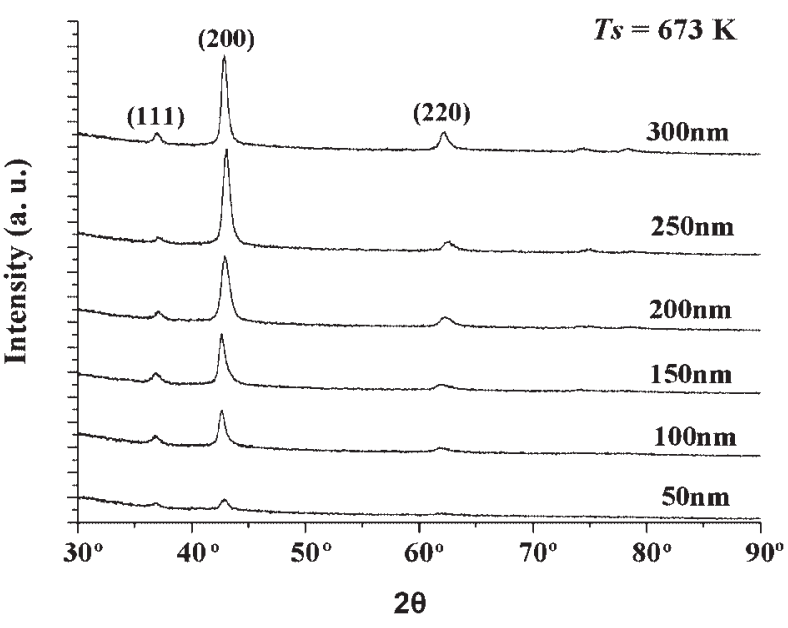

Fig. 1 X-ray diffraction patterns for different thickness of $\mathrm{NiO}$ films that were deposited on substrate at temperature of (a) $303 \mathrm{~K}$, (b) $673 \mathrm{~K}$.

oxygen, with thickness in the range from 50 to $300 \mathrm{~nm}$. Figure 1(a) shows the films deposited on substrates at $303 \mathrm{~K}$. Figure 1(b) shows the films deposited on substrates at $673 \mathrm{~K}$. The different peaks are indexed and the values of interplanar spacing $d$ are calculated and compared with standard 2 theta and $d$ values (2003 JCPDS database No: 89-7130). Table 1 and 2 present the calculated $d$ values and the corresponding indices, respectively.

The peak intensity increases with the film thickness and the $\mathrm{X}$-ray spectra are polycrystalline in nature. Also, the X-ray and electron diffraction patterns indicate that the films deposited on the glass substrates maintained at 303 and at $673 \mathrm{~K}$ have an $\mathrm{NaCl}$-type structure. The XRD pattern of $\mathrm{NiO}$ films prepared at these two substrate temperatures are compared. Those films deposited at a substrate temperature of $303 \mathrm{~K}$ had (111) preferential planes and those films deposited at $673 \mathrm{~K}$ had (200) preferential planes.

The dependence of crystallographic orientation on the substrate temperature of 303 and $673 \mathrm{~K}$ for NiO films might be explained as follows. The crystal orientation of the film is determined by the method for growth of the nuclei. In the deposition of oxide films, the films initially nucleated in a 
Table 1 Structural information obtained from XRD patterns for NiO films of different thickness deposited at room temperature (303 K) that compared with JCPDS-No: 89-7130. (Ref. 2003 JCPDS database)

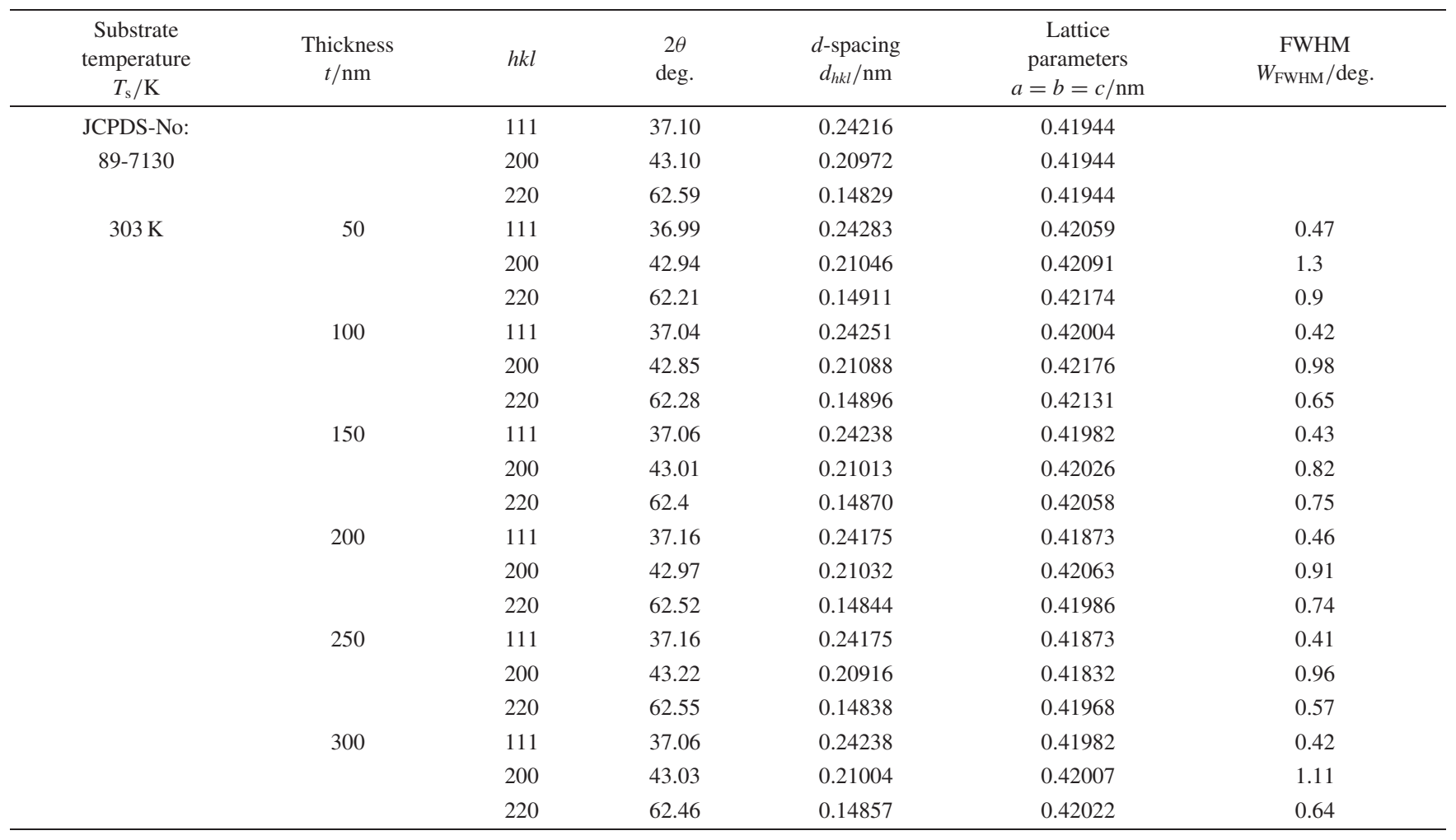

Table 2 Structural information obtained from XRD patterns for NiO films of different thickness deposited at higher temperature (673 K) that compared with JCPDS-No: 89-7130. (Ref. 2003 JCPDS database)

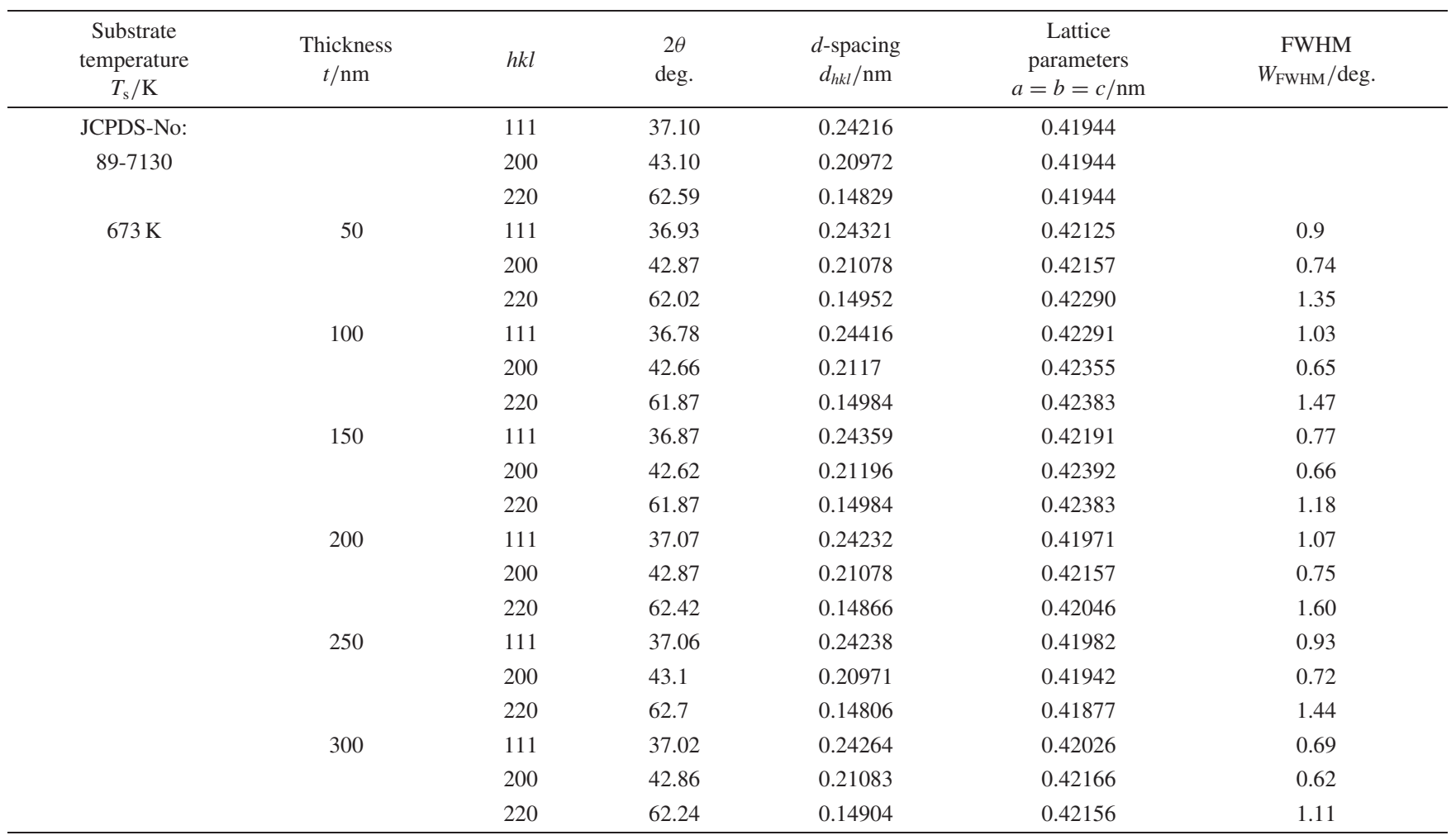

random orientation. When the film grows from the initial nuclei, the crystal plane of the nuclei with minimum surface free energy may remain parallel to the film surface, because the growth rate of the crystal plane with minimum surface free energy is lower than of the other crystal plane. In an ionic crystal of $\mathrm{NiO}$ with NaCl-type crystal structure, crystallographic orientation of the film is affected by the arrangement of $\mathrm{O}^{2-}$ when active species of nickel and oxygen, which are 
produced by sputtering process, collide separately with the growing film surface. ${ }^{1,23)}$ This is because $\mathrm{NiO}$ has no directivity of combination between $\mathrm{Ni}^{2+}$ and $\mathrm{O}^{2-}$, and the radius of $\mathrm{O}^{2-}(0.140 \mathrm{~nm})$ is larger than that of $\mathrm{Ni}^{2+}$ $(0.069 \mathrm{~nm})$. In $\mathrm{NiO}$ with $\mathrm{NaCl}$-type crystal structure, on the other hand, (111) plane is the most densely packed plane of $\mathrm{O}^{2-}$ for $\mathrm{NiO}$ crystal structure. It indicates that the (111) orientation minimizes the surface free energy of growing $\mathrm{NiO}$ film in this case. The (100) plane is the most densely packed plane among the planes composed of both $\mathrm{Ni}^{2+}$ and $\mathrm{O}^{2-}$, indicating that the $(100)$ orientation minimizes the surface energy of growing $\mathrm{NiO}$ films in this case. When the deposition is conducted in $\mathrm{O}_{2}$, it may be controlled by the arrangement of $\mathrm{O}^{2-}$, resulting (111) orientation of the $\mathrm{NiO}$ films. When $\mathrm{Ni}$ atoms or $\mathrm{NiO}$ molecules are sputtered more efficiently than oxygen atoms, (111)-oriented $\mathrm{NiO}$ film maybe difficult to obtain because the growth layer is composed of a mixture of $\mathrm{Ni}^{2+}$ and $\mathrm{O}^{2-}$ under this condition. Fujii et al. ${ }^{1)}$ prepared $\mathrm{NaCl}$-type $\mathrm{NiO}$ films on glass substrates at $400^{\circ} \mathrm{C}$ by PE-MOCVD. The (111) and (100) preferred orientations of $\mathrm{NiO}$ films were controlled by changing the $\mathrm{O}_{2}$ flow rates. The (111)-orientated $\mathrm{NiO}$ film was obtained at lower $\mathrm{O}_{2}$ flow rates, and (100)-orientated $\mathrm{NiO}$ film was obtained at higher $\mathrm{O}_{2}$ flow rates. Ryu et al. ${ }^{23)}$ observed that the $\mathrm{NiO}$ films deposited on $\mathrm{Si}(100)$ substrate at room temperature in different ratios of $\mathrm{O}_{2}$ to Ar by $\mathrm{RF}$ magnetron sputtering had (100)-oriented $\mathrm{NiO}$ film in an Ar atmosphere and (111)-oriented film in an $\mathrm{O}_{2}$ atmosphere. Kang et al. ${ }^{24)}$ prepared $\mathrm{NiO}$ films with $\mathrm{Ni}\left(\mathrm{C}_{5} \mathrm{H}_{5}\right)_{2} / \mathrm{O}_{2}$ at various temperatures and $\mathrm{O}_{2}$ flow rates by chemical vapor deposition. The (111)-orientated $\mathrm{NiO}$ film was obtained at the low deposition temperature region $(<548 \mathrm{~K})$, low nickel content in nickel oxide, and low grain size. The (100)-orientated $\mathrm{NiO}$ film was obtained at the high deposition temperature region (>548 K), high nickel content in nickel oxide, and high grain size. These different methods indicate that the $\mathrm{NiO}$ film texture depends on the oxygen content as well as on the deposition temperature. In our study, nickel oxide $(\mathrm{NiO})$ films were deposited onto glass substrates by RF magnetron sputtering in a pure oxygen atmosphere. The (111)-oriented $\mathrm{NiO}$ film was obtained at room temperature of $303 \mathrm{~K}$, and (100)-oriented $\mathrm{NiO}$ film was obtained at higher temperature of $673 \mathrm{~K}$. This result can be attributed to a minimum surface mobility of the nuclei at higher substrate temperature of $673 \mathrm{~K}$. At higher substrate temperature, the sputtered atoms obtain more kinetic energy when they arrive at the substrate surface. Also extra thermal energy is provided by the heated substrate. The mobility of atoms and clusters, which is in proportion to their energy, on the substrate will be increased with increasing the substrate temperature. It may favor the growth of the films along some simple crystal planes such as (100) and (001). It is suggested that the $\mathrm{NiO}$ molecules are sputtered more efficiently than oxygen atoms. It is easier to obtain (100)-oriented $\mathrm{NiO}$ film because the growth layer is composed of a mixture of $\mathrm{Ni}^{2+}$ and $\mathrm{O}^{2-}$ under higher substrate temperature.

In Fig. 2, $\beta \cos \theta / \lambda$ is plotted versus $\sin \theta / \lambda$ for $\mathrm{NiO}$ films deposited on substrate temperatures of 303 and $673 \mathrm{~K}$. The effective crystallite size that has taken the strain into account can be estimated from the extrapolation of the plot shown in (a)

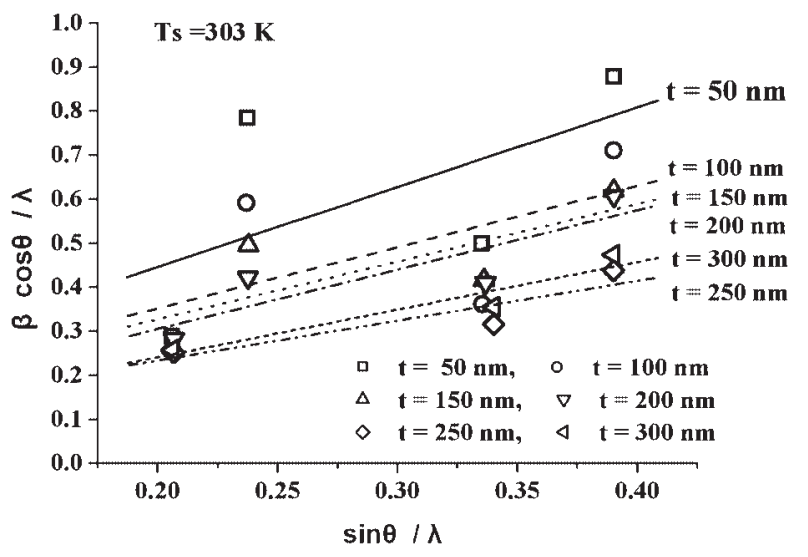

(b)

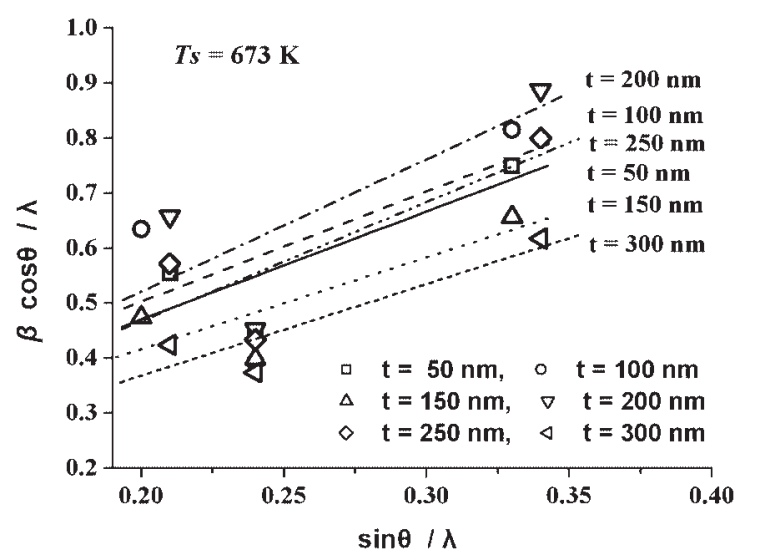

Fig. 2 Williamson-Hall plots of $\mathrm{NiO}$ films deposited on substrate at temperatures of (a) $303 \mathrm{~K}$, (b) $673 \mathrm{~K}$.

Fig. 2. The slope of the fitted line indicates the presence of strain in the $\mathrm{ZnO}$ crystal lattice. Transmission electron microscopy was also used to observe the microstructure of the NiO films. Figure 3 shows the transmission electron micrograph (TEM) and transmission electron diffraction patterns of $\mathrm{NiO}$ films deposited at room temperature $(303 \mathrm{~K})$ and at $673 \mathrm{~K}$, with a thickness of about $200 \mathrm{~nm}$. The crystallite sizes were found in nanoscale and estimated at about $20-30 \mathrm{~nm}$. The crystallite sizes were estimated from Williamson-Hall plot, which is similar to that observed by TEM. Table 3 presents the crystallite size $(L)$, density $(D)$, strain $(\varepsilon)$, dislocation density $(\delta)$ and stacking fault probabilities $(\alpha)$. Figure 4 plots the variation of the crystallite size $(L)$ and strain $(\varepsilon)$ with the thickness of the films. Figure 5 plots the variation of dislocation density $(\delta)$ and stacking fault probabilities $(\alpha)$ with thickness.

The crystallite size increases with the thickness of the films and strain decreases with the thickness of the films, as shown in Fig. 4. The dislocation density and the stacking fault probabilities, all decrease as the thickness increase as shown in Fig. 5. Figure 6 shown the nature of dislocations and stacking faults in $\mathrm{NiO}$ films were observed by high-resolution transmission electron microscopy (HR-TEM).

The increase in the crystallite size may be caused by a columnar grain growth in the structure. The crystallite sizes 
(a)

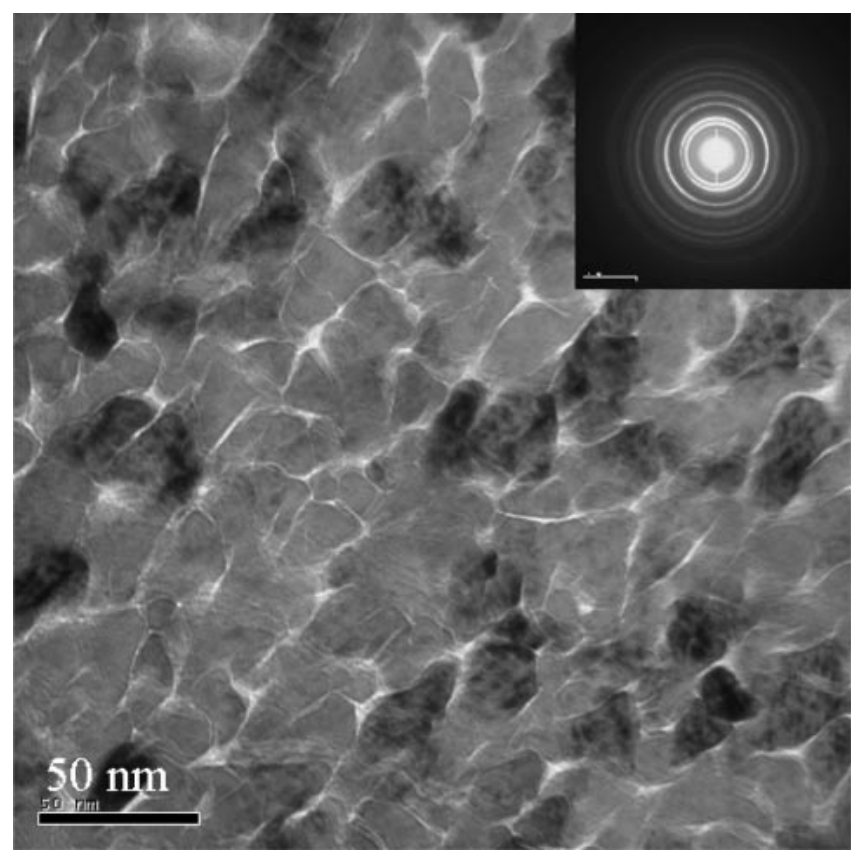

(b)

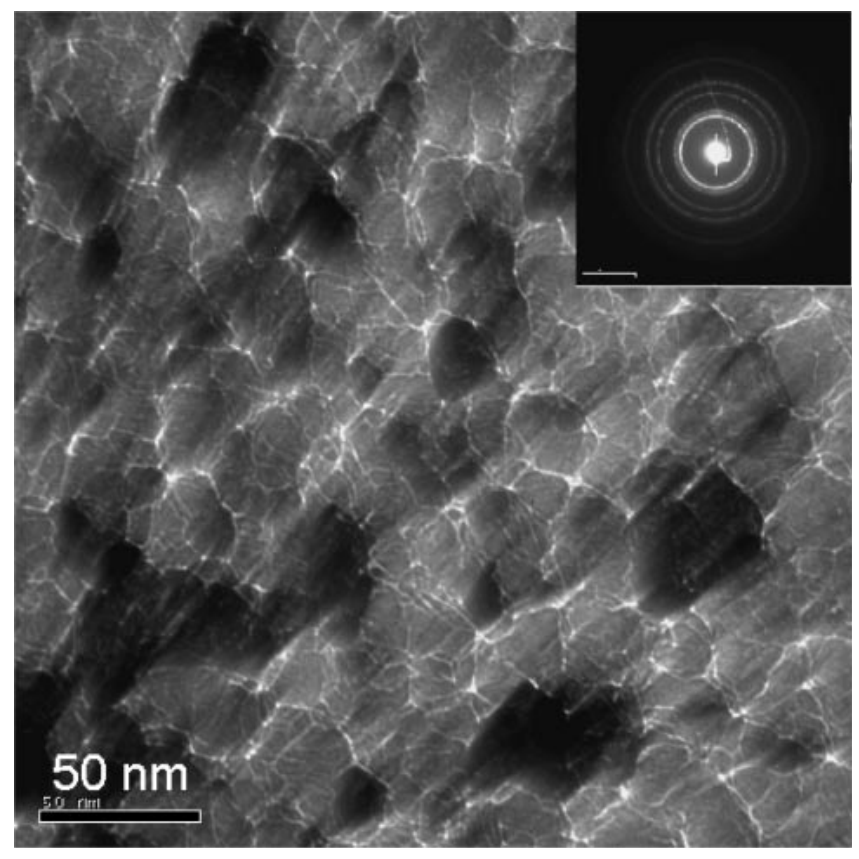

Fig. 3 TEM photographs of NiO films deposited on substrate at temperatures of (a) $303 \mathrm{~K}$, (b) $673 \mathrm{~K}$, and a thickness of about $200 \mathrm{~nm}$.

of $\mathrm{NiO}$ films deposited at $673 \mathrm{~K}$ were smaller than those deposited without heating $(303 \mathrm{~K})$ which fact may be attributed to the formation of new smaller crystallites on the larger grains. The FWHM was observed to decrease as the thickness of the film increased. The result reveals the crystallization approaches more perfect as the film was increased. This is due to decrease the internal micro-strain in the films and the increase in the crystallite size. ${ }^{15,25)}$ Table 3 compares the crystallite size $(L)$, the dislocation density $(\delta)$, the stacking fault probabilities $(\alpha)$ and the strain $(\varepsilon)$ of the
$\mathrm{NiO}$ films of different thickness on glass substrates. The crystallite size increases but the dislocation density decreases as the film thickness increases. Increasing the thickness, both the micro-stresses and the dislocation density existing in the film decrease. The reliefs of the stresses built up in the films leads to reduction in the interplanar spacing, and thus minimize the stacking fault probability in the films. ${ }^{26)}$ During the increase of the film thickness, the dislocation density and the microstrain are reduced because stress is released in the films by simultaneously annealing during deposition. Also the crystallite sizes initially gradual increase with film thickness and finally to a saturation value. The cumulative effect of the decrease in the microstrain and the dislocation density can be used to explain the gradual reduction in the stacking fault of the films with increasing film thickness. ${ }^{26)}$

\subsection{Electrical properties}

Figure 7 shows the dependence of resistivity $(\rho)$ and carrier concentration $(N)$ on the thickness of the $\mathrm{NiO}$ films that were deposited on substrate at the temperatures of 303 and $673 \mathrm{~K}$. Figure 7 (a) shows the resistivity and carrier concentration of the as-deposited films prepared on unheated substrate $(303 \mathrm{~K})$. The resistivity is seen to increase from $0.84 \times 10^{-2}$ to $2.2 \times 10^{-2} \Omega \mathrm{m}$ as the film thickness is increased from 50 to $300 \mathrm{~nm}$. The carrier concentration is also seen to decrease from $15.3 \times 10^{18}$ to $8.94 \times 10^{18} \mathrm{~cm}^{-3}$ as the film thickness is increased from 50 to $300 \mathrm{~nm}$. It can be explained with the fact that resistivity is known to be inversely proportional to the carrier concentration. Figure 7(b) shows the resistivity and carrier concentration of the film prepared on the heated substrate of $673 \mathrm{~K}$. The resistivity is seen to increase from $1.63 \times 10^{-2}$ to $11.09 \times 10^{-2} \Omega \mathrm{m}$ as the film thickness is increased from 50 to $300 \mathrm{~nm}$. The carrier concentration is also seen to decrease from $10.6 \times 10^{18}$ to $0.08 \times 10^{18} \mathrm{~cm}^{-3}$ as the film thickness is increased from 50 to $300 \mathrm{~nm}$. It can be seen that the film thickness has a much larger effect on the resistivity (10 times higher) as well as the carrier concentration (100 times lower) as the substrate is heated.

The conduction mechanism of the $\mathrm{NiO}$ film is believed to be related to the concentration of the electrical carrier, which is the oxygen vacancy existed in the structure. The electrical properties of $\mathrm{NiO}$ films are then associated with their microstructure and composition, and consequently, on the deposition environment. ${ }^{7-9)}$ To clarify this phenomenon, the film composition was investigated by AES. Figure 8 shows the AES depth profile of the $\mathrm{NiO}$ films prepared at substrate temperature of $303 \mathrm{~K}$ with film thickness of $250 \mathrm{~nm}$. For the AES profile, the atomic concentration near the surface is usually not a good indicator since it can be affected by the oxygen in the environment. The atomic concentration near the substrate is also not a good indicator since it can be affected by the silicon oxide existed on the surface of the substrate. For the middle region of the AES profile, it can be seen that oxygen concentration is decreased as the sputtering time is increased. The decrease in oxygen concentration indicates that oxygen vacancy is increased. However, the increase in sputtering time corresponds to a decrease in film thickness. Therefore, the AES profile does show that as film thickness increases, concentration of oxygen vacancy de- 
Table 3 Microstructural parameters for different thickness of NiO films deposited at different substrate temperatures. (Theory density of $\mathrm{NiO}: 6.72 \mathrm{~g} \mathrm{~cm}^{-3}$ )

\begin{tabular}{|c|c|c|c|c|c|c|}
\hline $\begin{array}{c}\text { Substrate } \\
\text { temperature } \\
T_{\mathrm{s}} / \mathrm{K}\end{array}$ & $\begin{array}{c}\text { Thickness } \\
t / \mathrm{nm}\end{array}$ & $\begin{array}{c}\text { Crystallite size } \\
L / \mathrm{nm}\end{array}$ & $\begin{array}{l}\text { Density } D \\
\mathrm{~g} \cdot \mathrm{cm}^{-3}\end{array}$ & $\begin{array}{c}\text { Strain, } \\
\varepsilon \times 10^{-3}\end{array}$ & $\begin{array}{c}\text { Dislocation } \\
\text { density, } \\
\delta \times 10^{15} \\
\operatorname{lin} \cdot \mathrm{m}^{-2}\end{array}$ & $\begin{array}{c}\text { Stacking } \\
\text { fault } \\
\text { probability } \\
\alpha\end{array}$ \\
\hline \multirow[t]{5}{*}{$303 \mathrm{~K}$} & 50 & 11.94 & 6.62 & 1.81 & 7.01 & 0.0795 \\
\hline & 100 & 13.42 & 6.64 & 1.39 & 5.55 & 0.0416 \\
\hline & 150 & 15.23 & 6.67 & 1.31 & 4.31 & 0.0264 \\
\hline & 250 & 40.77 & 6.71 & 1.02 & 0.60 & 0.0490 \\
\hline & 300 & 41.20 & 6.69 & 1.08 & 0.59 & 0.0264 \\
\hline \multirow[t]{5}{*}{$673 \mathrm{~K}$} & 50 & 11.17 & 6.56 & 1.91 & 8.01 & 0.1471 \\
\hline & 100 & 13.53 & 6.52 & 2.09 & 5.46 & 0.2841 \\
\hline & 150 & 15.00 & 6.52 & 1.72 & 4.44 & 0.3103 \\
\hline & 200 & 25.35 & 6.68 & 2.41 & 1.56 & 0.1471 \\
\hline & 300 & 40.39 & 6.62 & 1.72 & 0.61 & 0.1536 \\
\hline
\end{tabular}

(a)

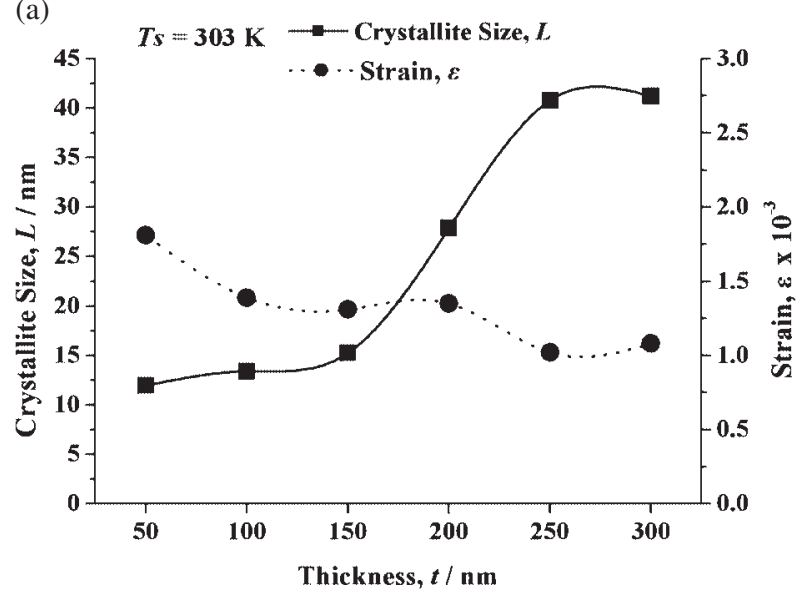

(b)

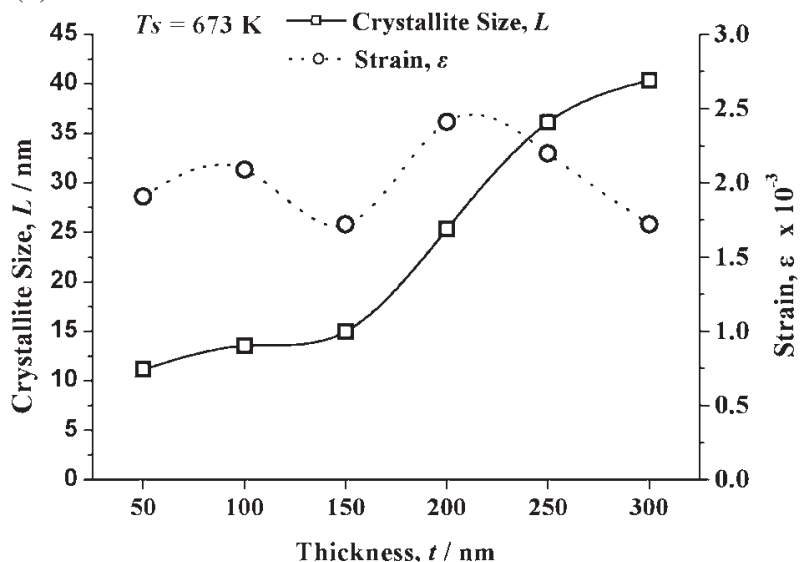

Fig. 4 The crystallite size and lattice strain of the $\mathrm{NiO}$ films at different substrate temperature of (a) $303 \mathrm{~K}$, (b) $673 \mathrm{~K}$.

creases. This leads to the conclusion that the dominant factor for the resistivity of the $\mathrm{NiO}$ films is oxygen vacancy. Hence the resistivity of $\mathrm{NiO}$ film is increased with an increase in film thickness. (a)

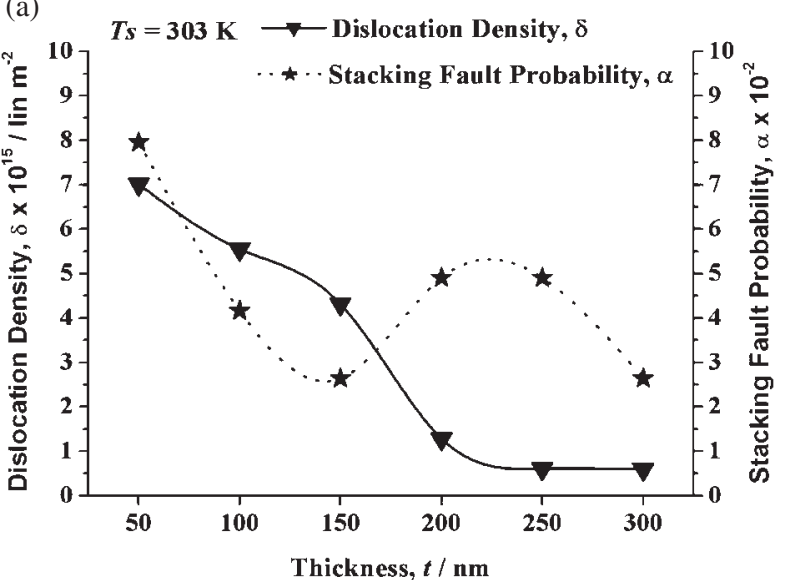

(b)

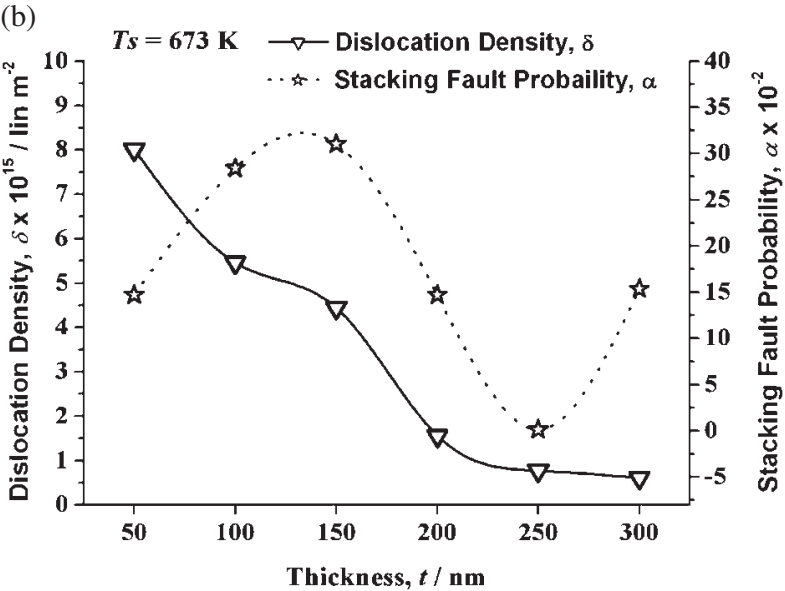

Fig. 5 Dislocation density and stacking fault probability against film thickness for $\mathrm{NiO}$ films that were deposited at different substrate temperature: (a) $303 \mathrm{~K}$, (b) $673 \mathrm{~K}$.

\section{Conclusion}

The relationships between the thickness of $\mathrm{NiO}$ films and structural and electrical properties are studied. The thicker 
(a)

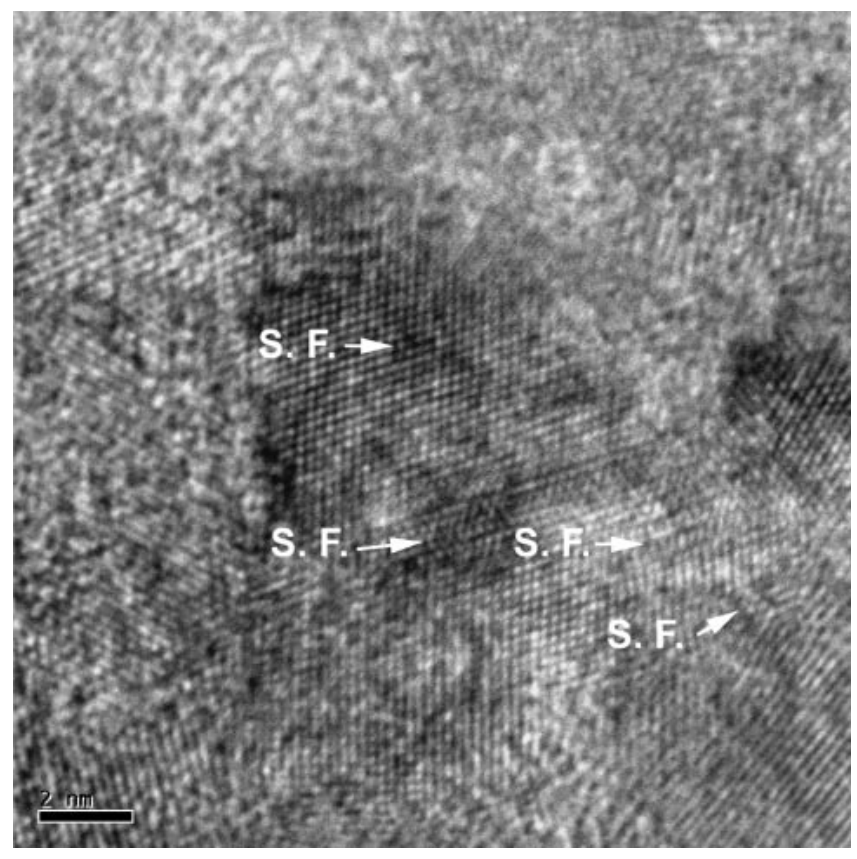

(b)

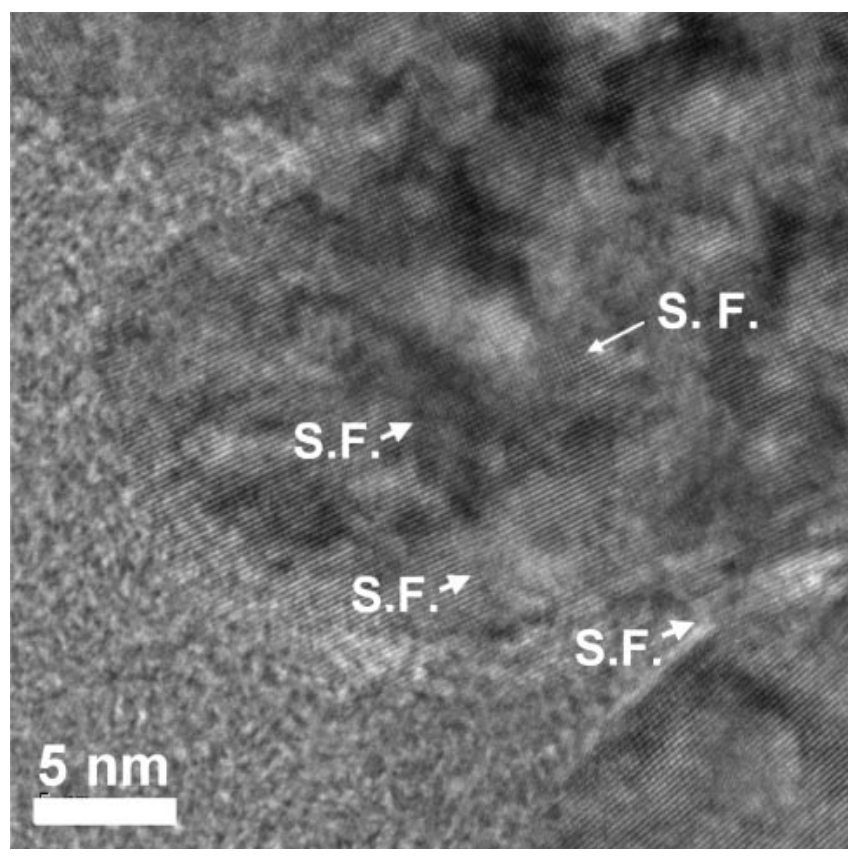

Fig. 6 HR-TEM lattice images of NiO films prepared at different substrate temperature: (a) $303 \mathrm{~K}$, (b) $673 \mathrm{~K}$.

films of NiO develop more perfect microstructures. The crystallite sizes increaser as the thickness of the film increases. The variation of the dislocation density and the stacking fault probabilities and strain decrease as the thickness increases. Stresses in the layers and the dislocation density decrease because the stresses that have built-up in the layers are released as the thickness increases. The resistivity of $\mathrm{NiO}$ film is increased with an increase in film thickness, which is related to the decrease of carrier concentration with film thickness. The NiO film with a thickness of $200 \mathrm{~nm}$ has a
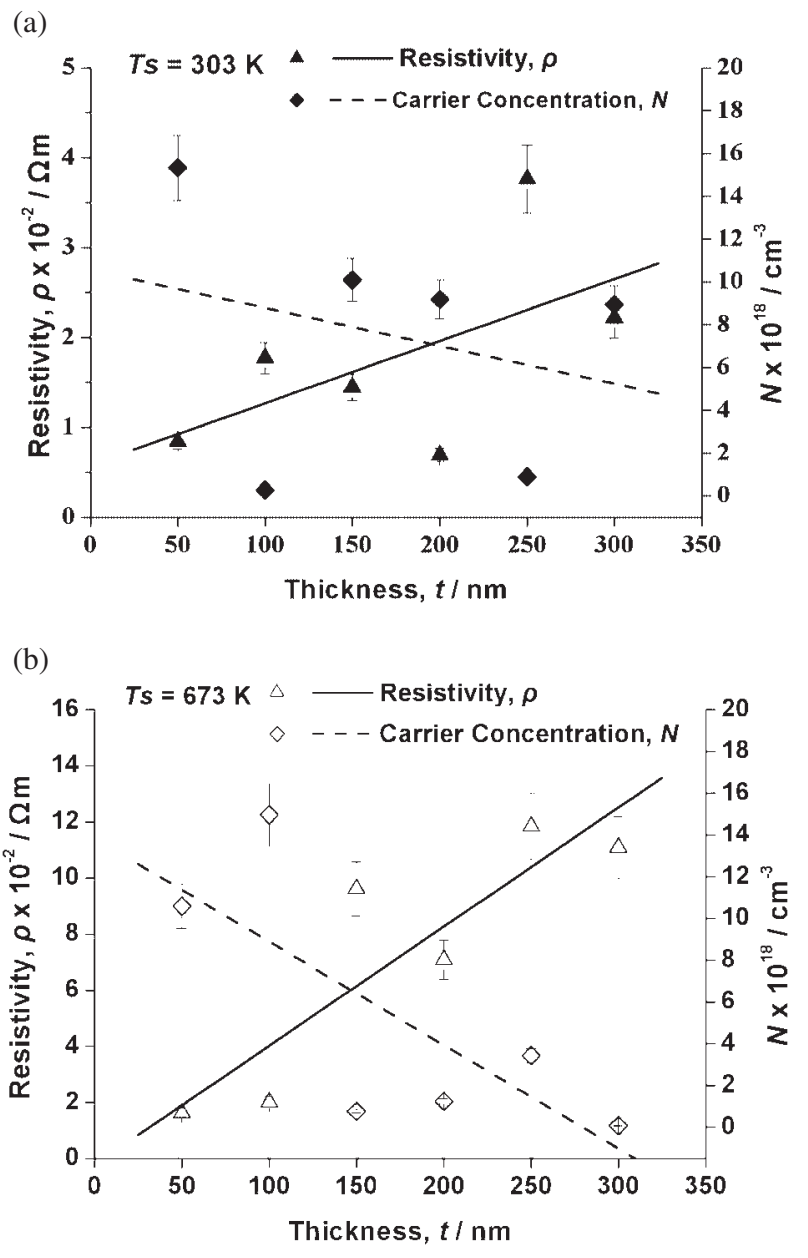

Fig. 7 Dependence of electrical resistivity and carrier concentration on the thickness of $\mathrm{NiO}$ films were deposited on substrate at temperature of (a) $303 \mathrm{~K}$, (b) $673 \mathrm{~K}$.

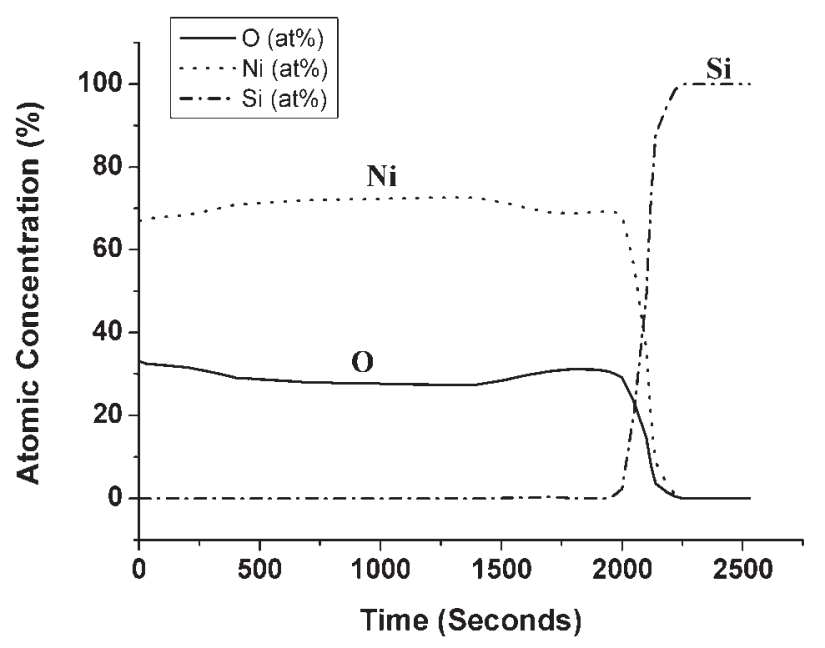

Fig. 8 AES depth profile of $\mathrm{NiO}$ films prepared at substrate temperature of $303 \mathrm{~K}$ with film thickness of $250 \mathrm{~nm}$.

minimum resistivity of $0.69 \times 10^{-2} \Omega \mathrm{m}$ when deposited at substrate temperature of $303 \mathrm{~K}$. 


\section{Acknowledgments}

The authors would like to thank the National Science Council in Taiwan for financially supporting this research under Grant No. NSC93-NU-7-006-002 \& NSC93-2216-E168-006.

\section{REFERENCES}

1) E. Fujii, A. Tomozawa, H. Torii and R. Takayama: Jpn. J. Appl. Phys. 35 (1996) L328-L330.

2) H. Sato, T. Minami, S. Takata and T. Yamada: Thin Solid Films 236 (1993) 27-31.

3) M. Kitao, K. Izawa, K. Urabe, T. Komatsu, S. Kuwano and S. Yamada: Jpn. J. Appl. Phys. 33 (1994) 6656-6662.

4) H. Kumagai, M. Matsumoto, K. Toyoda and M. Obara: J. Mater. Sci Lett. 15 (1996) 1081-1083.

5) P. Puspharajah, S. Radhakrishna and A. K. Arof: J. Mater. Sci. 32 (1997) 3001-3006

6) E. Fujii, A. Tomozawa, S. Fujii, H. Torii, M. Hattori and R. Takayama: Jpn. J. Appl. Phys. 32 (1993) L1448-L1450.

7) O. Kohmoto, H. Nakagawa, F. Ono and A. Chayahara: J. Magn. \& Magn. Mater. 226-230 (2001) 1627-1630.

8) Y. M. Lu, W. S. Hwang and J. S. Yang: Surf. Coat. Technol. 155 (2002) $231-235$

9) Y. M. Lu, W. S. Hwang, J. S. Yang and H. C. Chuang: Thin Solid Films 420-421 (2002) 54-61.

10) I. Hotový, J. Huran, L. Spiess, J. Liday, H. Sitter and Š. Haščík:
Vacuum 69 (2003) 237-242.

11) M. Rusu: Appl. Phys. A 66 (1998) 357-361.

12) J. Rodríguez, M. Gómez, J. Ederth, G. A. Niklasson and C. G. Granqvist: Thin Solid Films 365 (2000) 119-125.

13) M. Sirena, L. Steren and J. Guimpel: Thin Solid Films 373 (2000) 102_106.

14) D. P. Padiyan, A. Marikani and K. R. Murali: Mater. Chem. Phys. 78 (2002) 51-58.

15) S. Lalitha, R. Sathyamoorthy, S. Senthilarasu, A. Subbarayan and K. Natarajan: Sol. Energy Mater. Sol. Cells 82 (2004) 187-199.

16) K. S. Ahn, Y. C. Nah and Y. E. Sung: J. Vac. Sci. Technol., A 20 (2002) 1468-1474.

17) B. D. Cullity and S. R. Stock: Elements of X-Ray Diffraction, 3rd ed., (New Jersey: Prentice Hall, 2001).

18) G. K. Williamson and W. H. Hall: Acta Metall. 1 (1953) 22-31.

19) B. H. Hwang and S. Y. Chiou: Thin Solid Films 304 (1997) 286-293.

20) U. Pal, D. Samanta, S. Ghoral, B. K. Samantaray and A. K. Chaudhuri: J. Phys. D: Appl. Phys. 25 (1992) 1488-1494.

21) B. E. Warren and E. P. Warekois: Acta Metall. 3 (1955) 473-479.

22) J. P. Schaffer, A. Saxena, S. D. Antolovich, T. H. Sanders Jr. and S. B. Warner: The Science and Design of Engineering Materials, 2nd ed., (McGraw-Hill International, 1999) pp. 65-75.

23) H. W. Ryu, G. P. Choi, W. S. Lee and J. S. Park: J. Mater. Sci. Lett. 39 (2004) 4375-4377.

24) J. K. Kang and S. W. Rhee: Thin Solid Films 391 (2001) 57-61.

25) N. El-Kadry, A. Ashour and S. A. Mahmoud: Thin Solid Films 269 (1995) 112-116

26) T. Mahalingam, V. S. John, G. Ravi and P. J. Sebastian: Cryst. Res. Technol. 37 (2002) 329-339. 